\title{
Bronchial hyperresponsiveness and adult onset wheeze: the influence of atopy
}

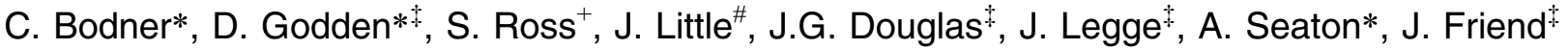

Bronchial hyperresponsiveness and adult onset wheeze: the influence of atopy. C. Bodner, D. Godden, S. Ross, J. Little, J.G. Douglas, J. Legge, A. Seaton, J. Friend. C) ERS Journals Ltd 1999.

ABSTRACT: The commonly held belief that adult onset wheezing illness is primarily nonatopic in nature suggests that the role of atopy in the pathophysiology of bronchial hyperresponsiveness (BHR) in adult onset wheeze may be minimal.

This study examined risk factors for BHR (BHR: provocative dose causing a $20 \%$ fall in forced expiratory volume in one second PD20 $\leq 16.38 \mu$ mol methacholine) among 82 subjects with adult onset wheeze and among 191 subjects who had never wheezed. Subjects were identified from a cohort of subjects aged 39-45 yrs who were known to have had no childhood wheeze and who were involved in a 30 yr follow-up survey. Risk factors for BHR were examined among all subjects with BHR and among subjects with BHR stratified according to whether or not they had ever wheezed.

The prevalence of BHR was $40 \%(33 / 82)$ among the subjects with adult onset wheeze and $11 \%(21 / 191)$ among the subjects who had never wheezed. Lower baseline lung function (odds ratio $(\mathrm{OR})=0.94 ; 95 \%$ confidence interval $(\mathrm{CI})=0.92-0.97$ per unit forced expiratory volume (FEV1)\% predicted) and atopy $(\mathrm{OR}=7.23 ; \mathrm{Cl}=2.53$ 20.64 for all three measures of atopic compared to nonatopic) were associated with BHR, while smoking and family history showed no statistically significant relation to BHR. This pattern was also apparent in analyses stratified by symptom status. A family history of atopy increased the risk that BHR was accompanied by wheezing symptoms $(O R=4.75 ; C I=1.53-14.72$ for more than one affected relative compared to no affected relatives).

These findings suggest that atopy is associated with bronchial hyperresponsiveness in adults known to have had no childhood wheeze. A familial factor reflecting genetic influences and/or shared environmental factors may influence whether bronchial hyperresponsiveness is associated with symptoms.

Eur Respir J 1999; 14: 335-338.

Bronchial hyperresponsiveness (BHR) in adults who are known to have had no childhood wheezing may be associated with different underlying factors compared to BHR in children. Atopy correlates with both the degree and persistence of BHR in childhood [1]. By contrast, it has been suggested that adult onset wheezing illness is primarily nonatopic in nature [2]. If this were true, it would be expected that the role of atopy in the pathophysiology of BHR in adult onset disease would be minimal. Atopy has been found to be associated with higher degrees of airway responsiveness among adults; however, the majority of these data come from general population samples in whom age of onset of respiratory symptoms has not been considered [3]. In one longitudinal study involving a cohort of males in Boston, MA, USA who were screened for respiratory diagnoses at entry, BHR measured in 778 men aged 41-86 yrs after 20 yrs follow-up was positively associated with atopy [4]. It has previously been shown in a follow-up of a community cohort that amongst the individuals who wheezed in childhood (i.e. at age 10-14 yrs) atopy was an important predictor of bronchial hyperresponsiveness and the persistence of symptoms in adulthood [5]. The current study examined risk factors
*Dept of Environmental and Occupational Medicine, University of Aberdeen, Aberdeen, UK. Dept of Thoracic Medicine, Aberdeen Royal Infirmary, Aberdeen, UK. ${ }^{+}$Health Services Research Unit, University of Aberdeen, Aberdeen, UK. " Dept of Medicine and Therapeutics, University of Aberdeen, Aberdeen, UK.

Correspondence: C. Bodner, Dept of Environmental and Occupational Medicine, University of Aberdeen, Aberdeen, Scotland, AB25 2ZD. Fax: 1224662990

Keywords: Adult onset

atopy

bronchial hyperresponsiveness epidemiology

risk factors

Received: September 121998 Accepted after revision May 231999

This study was supported by grants from the National Asthma Campaign, the Medical Research Council and Aberdeen Royal Hospitals Trust. Bodner received support from the Canadian Nurses' Respiratory Society and the Canadian Lung Association. for BHR in adulthood among individuals in this cohort who had no childhood wheezing symptoms.

\section{Methods}

A 1964 random community survey in Aberdeen of 2,511 children aged 10-14 yrs identified 121 children with asthma and 167 with wheeze in the presence of infection. The outcome at age 34-40 yrs of these 288 children with wheeze, together with that of 167 children selected from those who were asymptomatic, has been described previously [6]. The current authors have recently attempted to contact the remaining 2,056 individuals now aged 3945 years: 1,542 of the 1,758 surviving subjects traced responded to the follow-up survey. Adult onset wheeze, defined as any occurrence of wheezing or whistling in the chest on or after age $15 \mathrm{yrs}$, was reported by $177(11.5 \%)$ subjects [7]. In a nested case control study, all 113 respondents with adult onset wheeze who resided locally and 267 comparison subjects randomly selected from among the respondents with no wheeze who lived locally were invited to take part in further investigations [8]. Ethical 
Table 1. - Risk factors for bronchial hyperreactivity

\begin{tabular}{|c|c|c|c|c|}
\hline & $\begin{array}{l}\text { No } \begin{array}{l}B H R \pm \text { wheeze } \\
(n=219)^{*}\end{array}\end{array}$ & $\begin{array}{c}\mathrm{BHR} \pm \text { wheeze } \\
(\mathrm{n}=54)^{\dagger}\end{array}$ & $\begin{array}{l}\mathrm{BHR}+\text { wheeze } \\
\quad(\mathrm{n}=33)^{\dagger}\end{array}$ & $\begin{array}{l}\text { BHR- no wheeze } \\
\quad(\mathrm{n}=21)^{\dagger}\end{array}$ \\
\hline \multicolumn{5}{|l|}{ Smoking habit } \\
\hline Never & $97(44 \%)$ & 1.0 & 1.0 & 1.0 \\
\hline Former & $56(26 \%)$ & $0.94(0.38-2.33)$ & $0.55(0.15-2.00)$ & $1.79(0.54-5.92)$ \\
\hline Current & $66(30 \%)$ & $1.61(0.74-3.49)$ & $1.92(0.76-4.85)$ & $1.39(0.40-4.80)$ \\
\hline \multicolumn{5}{|l|}{ Atopic status } \\
\hline No measures positive & $105(48 \%)$ & 1.0 & 1.0 & 1.0 \\
\hline Only one measure positive & $44(20 \%)$ & $0.81(0.31-2.13)$ & $1.01(0.32-3.20)$ & $0.61(0.11-3.25)$ \\
\hline Two measures positive & $56(26 \%)$ & $1.29(0.55-3.03)$ & $1.35(0.46-3.92)$ & $1.32(0.37-4.71)$ \\
\hline Three measures positive & $14(6 \%)$ & $7.23(2.53-20.64)$ & $7.35(1.81-29.94)$ & $8.70(2.39-31.66)$ \\
\hline Cat skin test positive & $28(13 \%)$ & $2.02(0.89-4.58)$ & $2.84(1.09-7.40)$ & $1.12(0.31-4.11)$ \\
\hline Total IgE IU $\cdot \mathrm{mL}^{-1} \log t$ & $3.3 \pm 1.3$ & $1.85(1.36-2.53)$ & $1.47(1.00-2.15)$ & $2.79(1.71-4.54)$ \\
\hline \multicolumn{5}{|l|}{ Family history } \\
\hline No family history & $129(59 \%)$ & 1.0 & 1.0 & 1.0 \\
\hline One affected relative & $53(24 \%)$ & $1.35(0.61-3.00)$ & $2.86(1.05-7.75)$ & $0.47(0.12-1.85)$ \\
\hline More than one affected relative & $37(17 \%)$ & $2.09(0.85-5.12)$ & $4.75(1.53-14.72)$ & $0.91(0.22-3.76)$ \\
\hline $\mathrm{p}$-value for trend & & 0.107 & 0.004 & 0.594 \\
\hline FEV1 \% predicted (per unit) & $112 \pm 14$ & $0.94(0.92-0.97)$ & $0.92(0.89-0.96)$ & $0.96(0.92-0.99$ \\
\hline
\end{tabular}

BHR diagnosed from a methacholine provocative dose causing a $20 \%$ fall in forced expiratory volume in one second $\leq 16.38 \mu$ mol. *: distribution of risk factors among subjects with no BHR, (number of subjects, with percentage of total subjects in parentheses). ${ }^{\dagger}:$ odds ratios (with 95\% CI confidence intervals in parentheses) adjusted for other factors shown with 'No BHR \pm wheeze' $(\mathrm{n}=219$ ) as reference group. ${ }^{\text {: }}$ skin test result for cat and total immunoglobulin (Ig)E entered into multivariate model simultaneously in place of summary variable of atopy, (odds ratios with confidence intervals in parentheses).

approval for the study was obtained from the Grampian Health Board and the University of Aberdeen Joint Ethical Committee and all participants gave informed consent.

Subjects were contacted in random order over a 7 month period from April to October 1995. An interview included questions about respiratory symptoms, socioeconomic status, smoking habit and family history of atopic disease. Social class, based on the subject's own occupation, was defined as manual or nonmanual using the 1991 UK Standard Occupational Classification (Office of Population Censuses and Surveys, London, H.M.S.O., 1991). For family history of atopic disease, each occurrence of asthma, eczema, or hayfever in parents and siblings was counted and a variable categorized as none affected, one affected and $>1$ affected relative.

Atopy was determined by skin reactivity, specific and total immunoglobin $(\mathrm{Ig}) \mathrm{E}$. Skin and specific IgE tests were expressed as positive if at least one antigen (house dust mite, cat or mixed grass pollen) showed a wheal diameter of $\geq 3 \mathrm{~mm}$ greater than the negative control or a radioallergosorbent test (RAST) class of $\geq 1$ (i.e. $\geq 0.35 \mathrm{IU} \cdot \mathrm{mL}^{-1}$ ). Total IgE results greater than $120 \mathrm{IU} \cdot \mathrm{mL}^{-1}$ were considered positive. Overall atopic status was expressed as a cumulative variable summing the positive measures.

Challenge tests were carried out using methacholine administered by the method of YAN et al. [9]. Subjects were asked not to use bronchodilator inhalers for $\geq 8 \mathrm{~h}$ before attending and they were excluded from the test if their baseline FEV 1 was $<70 \%$ of predicted. Methacholine responsiveness was expressed as positive for subjects whose FEV1 fell by $20 \%$ from baseline over the course of the test $(\mathrm{PD} 20 \mathrm{FEV} 1 \leq 16.38 \mathrm{mmol})$ [9].

The association of BHR with the independent variables was assessed by logistic regression with odds ratios (OR) and $95 \%$ confidence intervals $(\mathrm{CI})$ used to estimate relative risk. Although symptoms were used to select the subjects, in this paper BHR is the outcome of interest and symptom status or original grouping is treated as an additional independent variable. Analyses, using STATA Release 4 (Stata Corporation, College Station, TX, USA), were conducted for all subjects with BHR (BHR+) and for subjects with BHR stratified according to whether or not they had ever wheezed. The reference group included all subjects without BHR (BHR-).

\section{Results}

Complete data were obtained from 273 of the 380 subjects invited to participate: these included $82(73 \%)$ of the subjects with adult onset wheeze and 191 (72\%) of the subjects who had never wheezed. Although it was not possible to determine whether the participants were representative of all subjects with or without BHR in the whole population, the participants did not differ from those in the original symptom groups in terms of sex, smoking habit or social class. The prevalence of BHR was 40\% (33/82) among the subjects with adult onset wheeze and $11 \%(21 /$ 191) among the subjects who had never wheezed; $61 \%$ $(33 / 54)$ of the subjects with BHR had adult onset wheeze and $39 \%(21 / 54)$ had never wheezed.

The independent relationships between baseline characteristics and bronchial responsiveness are shown in table 1. Lower baseline lung function and atopy were associated with greater responsiveness among all the subjects with BHR, while smoking and family history showed no statistically significant relation to BHR. In the analyses stratified by symptom status, both symptomatic and asymptomatic BHR were associated with atopy and baseline lung function. Similar results were observed when BHR- subjects with wheeze were excluded from the reference group and when wheezing status was entered as a separate independent variable in the models. 
In models examining the independent effect of individual measures of atopy in place of the cumulative measure, higher total IgE levels were independently associated with BHR in all groups. Once the effect of total IgE was accounted for, skin test positivity to cat allergen was independently associated with symptomatic hyperresponsiveness, but there were no independent relationships between responsiveness and skin test reactivity to grass or house dust mite or any specific IgE results. Entered on their own, positive $\mathrm{IgE}$ binding to cat $(\mathrm{OR}=6.15 ; \mathrm{CI}=2.09-18.13)$ and grass $(\mathrm{OR}=2.82 ; \mathrm{CI}=1.09-7.31)$ allergen were independently associated with symptomatic but not asymptomatic hyperresponsiveness.

Symptomatic reactors were distinguished from asymptomatic reactors by their positive family history of atopic disease. Individuals with $\geq 1$ affected parent or sibling were significantly more likely to have bronchial hyperresponsiveness along with wheezing symptoms compared to those with no family history. Age, sex, and social class showed no relation to BHR.

The relationship between smoking and BHR appeared to vary with atopic status. The proportion of atopic subjects with BHR was $\sim 25 \%$ regardless of their smoking habits. However, the proportion of nonatopic subjects with BHR was significantly higher in those who smoked $(30 \%)$ compared to those who had never smoked $(4 \%)$ or who had stopped smoking (10\%).

\section{Discussion}

In this study, the prevalence of BHR was $40 \%$ among the subjects with adult onset wheeze and $11 \%$ among the subjects who had never wheezed. In one other study in which age of onset of wheezing symptoms was considered among 458 males in Boston, MA, USA (The Normative Aging Study), 50\% (5/10) of those reporting adult onset doctor-diagnosed asthma during the follow-up period 1961-1985 experienced a 20\% decline in FEV1 at or below a cumulative methacholine dose of $50 \mu \mathrm{mol} \mathrm{com-}$ pared to approximately $30 \%$ of the nonasthmatic subjects [10]. The higher prevalence of BHR among subjects with symptoms in the Boston study may be due in part to the different challenge method used and the exclusion of cases who reported wheeze other than doctor-diagnosed asthma.

Lower baseline lung function and atopy were independently associated with increased BHR in the present study. In analyses stratified by symptoms, the relationships between the independent variables and responsiveness were similar to those in the unstratified analyses. Family history of atopic disease and skin test positivity to cat were associated with symptomatic BHR, but showed no relation to asymptomatic BHR. Although smoking showed no statistically significant relation to responsiveness, current smoking was associated with a greater prevalence of BHR among nonatopic subjects. These findings are limited by the small number of subjects included in the analyses; the statistical power is too low to exclude relationships between BHR and family history or smoking.

While it is not possible to draw conclusions about BHR in the target population as a whole from these findings which were observed in subjects originally selected on the basis of wheeze, the relationships observed between BHR and other independent variables in this study are consistent with current knowledge and provide additional interesting information based on a unique population. The inverse relationship between baseline lung function and BHR observed in the present study is consistent with the findings of several studies conducted in adult populations. $[4,10,11]$. Although the role of atopy has been thought to be less important in adults than in children, several reports from the Normative Aging Study [10], which specifically addressed adult onset wheezing illness in a cohort of men followed since 1961, have shown a relationship between atopy and airway responsiveness [4, 12], including asymptomatic responsiveness [13]. When three measures of atopy were included in the present analyses simultaneously, apart from skin test positivity to cat allergen which was associated with symptomatic BHR, only the effect of total IgE remained significant. A close association between total IgE levels and wheezing illness, even after adjustment for other measures of atopy, has been noted in the present population [8] and in other adult populations [14]. In the Normative Aging Study [10], sensitization to cat allergen (but not sensitisation to dust mite, ragweed or mouse) was associated with adult onset asthma and predated methacholine hyperresponsiveness [12]. It is possible that dust mite sensitivity, which is strongly associated with childhood asthma [15], may play less of a role in symptomatic airway responsiveness which manifests later in life. Other potential allergic stimuli in adult onset disease may include bacteria in the respiratory tract or occupational exposures.

The association between a positive family history of atopic disease and symptomatic BHR noted in the present study is consistent with the findings of a recent study which showed that among 30 subjects with asymptomatic $\mathrm{BHR}$, all four individuals who developed symptoms over a $3 \mathrm{yr}$ follow-up period had a family history of asthma [16]. This familial element suggests that genetic influences and/or shared environmental factors, in conjunction with atopy, play a role in the subsequent development of symptoms among subjects with asymptomatic BHR.

As in the present study, there was evidence of an interaction between atopy and smoking in the Normative Aging Study [10], skin test positive smokers in the Boston cohort showing greater BHR than nonsmokers or skin test negative smokers [4]. The differences in the pattern of interaction observed in the two studies may be related to the fact that the Boston cohort was older (i.e. skin test positivity diminished with age) and contained very few smokers (i.e. only $13 \%$ were current smokers).

In conclusion, this study involving middle aged subjects who were known to have had no childhood wheezing illness demonstrated the previously reported overlap in bronchial hyperresponsiveness between symptomatic and asymptomatic groups. Furthermore, as in childhood, atopy was an important determinant of bronchial hyperresponsiveness. A familial factor reflecting genetic influences and/or shared environmental factors, in conjunction with atopy, may influence whether bronchial hyperresponsiveness is accompanied by symptoms.

Acknowledgements. The authors thank S. MacIntyre, D. Oldman and E. Zanre for co-operation in tracing the subjects; B. Calder for secretarial support; and the field staff for assistance with data collection. 


\section{References}

1. Burrows B, Sears MR, Flannery EM, Herbison GP, Holdaway MD, Silva PA. Relation of the course of bronchial hyperresponsiveness from age 9 to age 15 to allergy. Am J Respir Crit Care Med 1995; 152: 13021308.

2. Dodge RR, Burrows B. The prevalence and incidence of asthma and asthma-like symptoms in a general population sample. Am Rev Respir Dis 1980; 122: 567-575.

3. Weiss ST, Sparrow D, O'Connor GT. The inter-relationship among allergy, airways responsiveness and asthma. J Asthma 1993; 30: 329-349.

4. O'Connor GT, Sparrow D, Segal MR, Weiss ST. Smoking, atopy, and methacholine airway responsiveness among middle-aged and elderly men. Am Rev Respir Dis 1989; 140: 1520-1526.

5. Ross S, Godden DJ, Abdalla M, et al. Outcome of wheeze in childhood: the influence of atopy. Eur Respir J 1995; 8: 2081-2087.

6. Godden DJ, Ross S, Abdalla M, et al. Outcome of wheeze in childhood: symptoms and pulmonary function 25 years later. Am J Respir Crit Care Med 1994; 149: 106-112.

7. Bodner C, Ross S, Douglas G, et al. The prevalence of adult onset wheeze: longitudinal study. BMJ 1997; 314: 792-793.

8. Bodner CH, Ross S, Little J, et al. Risk factors for adult onset wheeze: a case control study. Am J Respir Crit Care Med 1998; 157: 35-42.

9. Yan K, Salome C, Woolcock AJ. Rapid method for measurement of bronchial responsiveness. Thorax 1983; 38: 760-765.

10. Sparrow D, O'Connor G, Colton T, Barry CL, Weiss ST. The relationship of nonspecific bronchial responsiveness to the occurrence of respiratory symptoms and decreased levels of pulmonary function. Am Rev Respir Dis 1987; 135: $1255-1260$

11. Ulrik CS. Bronchial responsiveness to inhaled histamine in both adults with intrinsic and extrinsic asthma: the importance of prechallenge forced expiratory volume in 1 second. J Allergy Clin Immunol 1993; 91: 120-126.

12. Litonjua AA, Sparrow D, Weiss ST, O'Connor GT, Long AA, Ohman JL. Sensitization to cat allergen is associated with asthma in older men and predicts new-onset airway responsiveness. Am J Respir Crit Care Med 1997; 156: 23-27.

13. Annema JT, Sparrow D, O'Connor GT, et al. Chronic respiratory symptoms and airway responsiveness to methacholine are associated with eosinophilia in older men: the Normative Aging Study. Eur Respir J 1995; 8: 62-69.

14. Burrows B, Martinez FD, Halonen M, Barbee RA, Cline MG. Association of asthma with serum IgE levels and skin-test reactivity to allergens. $N$ Engl J Med 1989; 320: 271-277.

15. Platts-Mills TAE, Sporik RB, Chapman MD, Heyman PW. The role of indoor allergens in asthma. Allergy 1995; 50(Suppl. 22): 5-12.

16. Laprise C, Boulet L. Asymptomatic airway hyperresponsiveness: a three-year follow-up. Am J Respir Crit Care Med 1997; 156: 403-409. 